\title{
TECHNIQUES FOR THE EXAMINATION OF THICK FILM RESISTOR MICROSTRUCTURES BY T.E.M.
}

\author{
D. J. PEDDER \\ Plessey Company Limited, Caswell, Northants, U.K.
}

(Received May 30, 1977)

\begin{abstract}
This paper discusses the preparation techniques which can be used for the examination of thick film resistor microstructures by Transmission Electron Microscopy. The application of this technique, including High Voltage Electron Microscopy and Electron Microscope Mass Analysis, to both Ruthenium Dioxide and Bismuth Ruthenate based thick film resistors, is considered.
\end{abstract}

\section{INTRODUCTION}

There has been considerable interest over the past decade in attempting to relate the microstructure of thick film resistors to available theoretical models for the conduction process. ${ }^{1-2}$ To date optical.and scanning electron microscopy techniques have been most commonly employed but suffer from limited resolu-

A

Original tile

B

Tile waxed to glass slide, $3 \mathrm{~mm}$ discs cut with $\mathrm{u} / \mathrm{s}$ drill

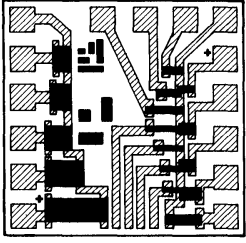

C

Disc removed and waxed to slide for grinding and polishing

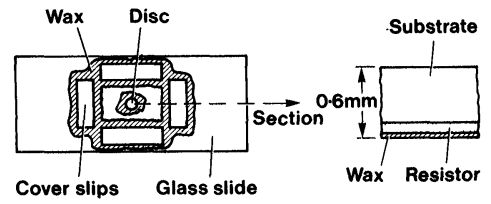

E

Nickel support grid glued onto disc with PVA

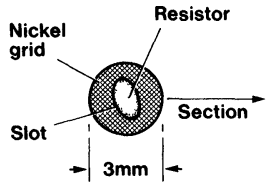

Nickel grid

PVA

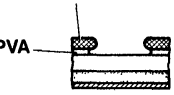

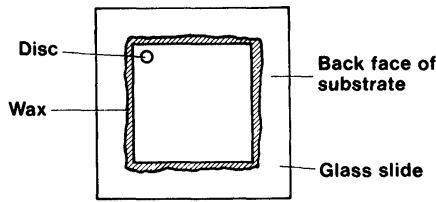

D Disc ground and polished to $\sim 25 \mu \mathrm{m}$ thickness

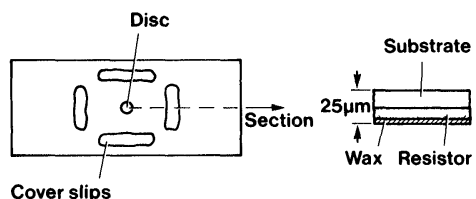

F

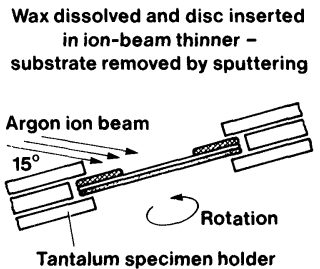

G

Final thin foil milled

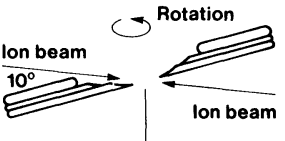

Perforation in resistor layer at controlled position and depth

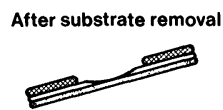

FIGURE 1 Specimen preparation technique, schematic. 
tion and the fact that only two-dimensional sectional information is obtained. In this paper, specimen preparation techniques are described for the examination of thick-film resistor microstructures by transmission electron microscopy (TEM). Modern TEM methods, including high voltage electron microscopy (HVEM) and electron microscopy mass analysis (EMMA) techniques, give very high resolution images of the structures $(\sim 1 \mathrm{~nm})$, together with crystallographic information on the crystalline phases present. Elemental analysis of small selected areas of the transmission samples (down to $0.2 \mu \mathrm{m}$ diameter) may be obtained using the EMMA instrument and with HVEM, where samples up to about $1 \mu \mathrm{m}$ in thickness may be examined, three dimensional images may be reconstructed from stereopairs taken in the microscope.

\section{SPECIMEN PREPARATION}

The technique for the preparation of the thinned samples is based on a combination of mechanical grinding and polishing followed by ion-beam thinning and the various stages are illustrated in Figure 1. The thick film substrate is waxed face down onto a glass slide and $3 \mathrm{~mm}$ discs cut from the areas of interest using an ultrasonic drill. The discs are removed and individually mounted face down on a second glass slide, surrounded by four pieces of glass cover slip to

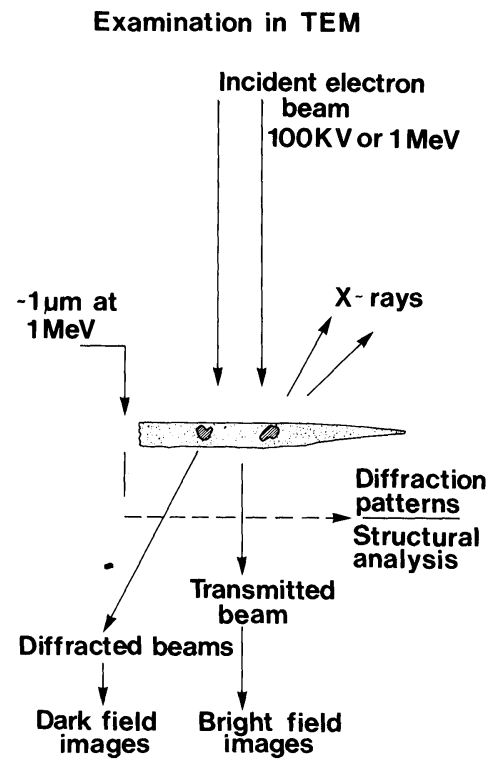

FIGURE 2 Interaction of the electron beam with the specimen in the electron microscope.

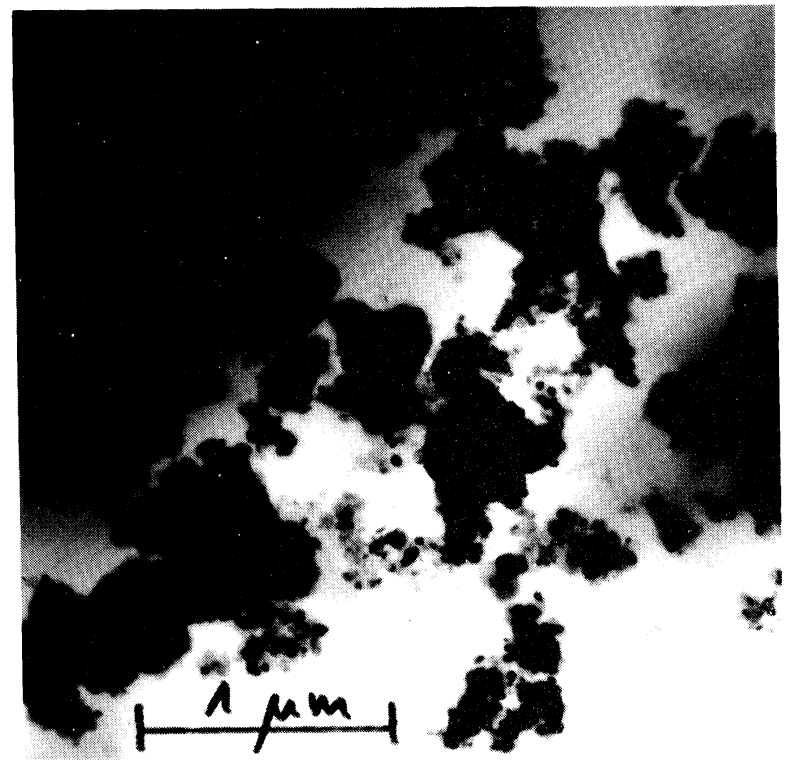

FIGURE 3 Bright field electron micrograph, Product A.

provide edge protection and limit the final grinding rate. The disc is then thinned mechanically by wet grinding on silicon carbide papers to a thickness of $\sim 50 \mu \mathrm{m}$. This is followed by polishing to a high quality surface finish and a final thickness of $25 \mu \mathrm{m}$ using diamond impregnated Hyprocel Pellon cloths (Engis Ltd.) and a water lubricant. A $3 \mathrm{~mm}$ diameter slotted nickel microscope support grid is then glued

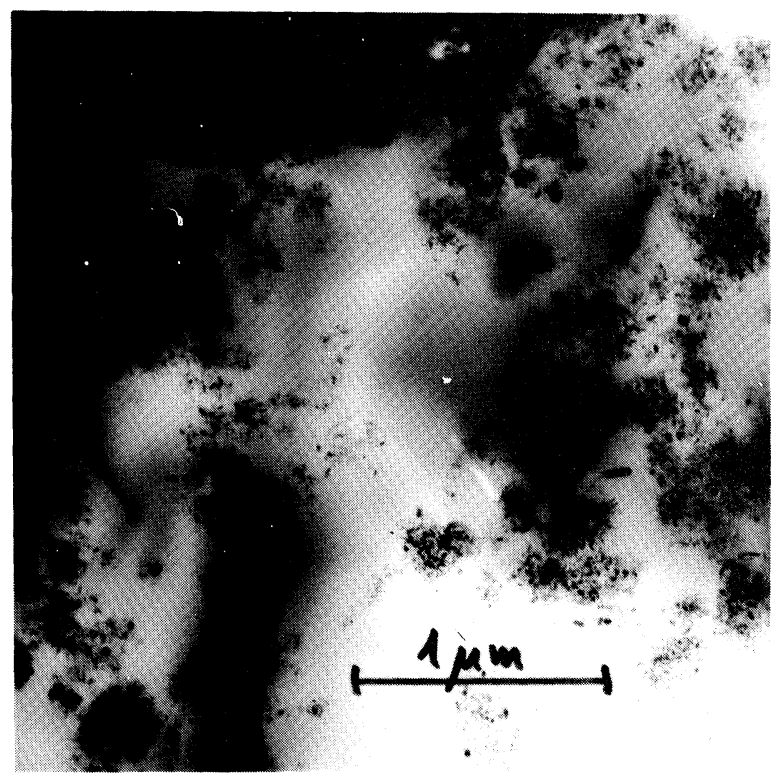

FIGURE 4 Bright field electron micrograph, Product B. 


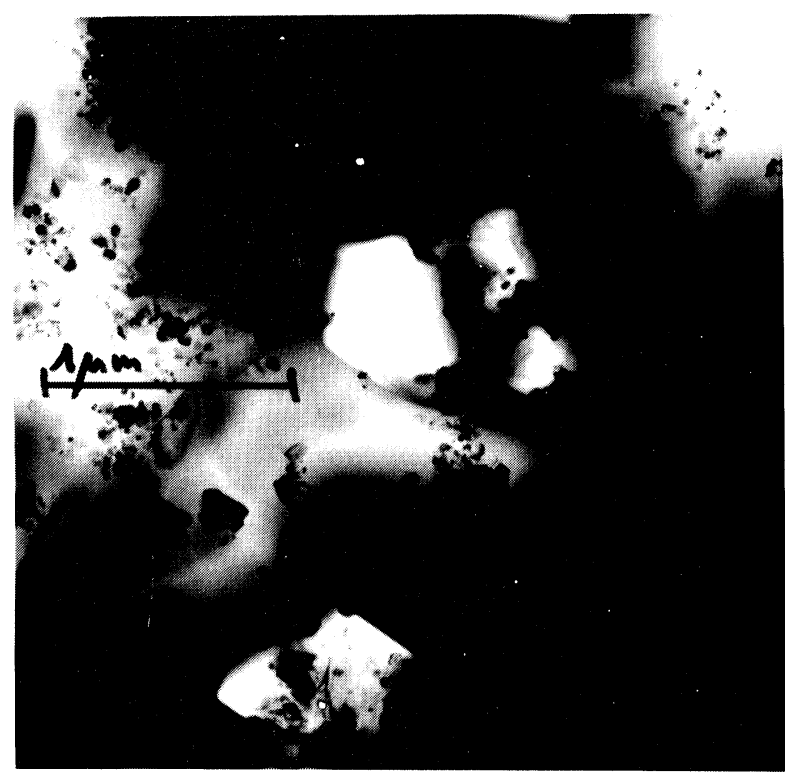

FIGURE 5 Bright field electron micrograph, Product C.

onto the polished disc with PVA. Following drying the wax holding the sample to the glass slide is dissolved in chloroform and the nickel grid with the thick-film resistor sample disc attached is inserted in an ion-beam thinner. Any residual alumina substrate is first removed by sputtering from one side of the sample only with $6 \mathrm{kV}$ argon ions (beam current $\sim 100 \mu \mathrm{A}$ ). The final thin foil is then milled by thinning from each side of the sample until the disc is

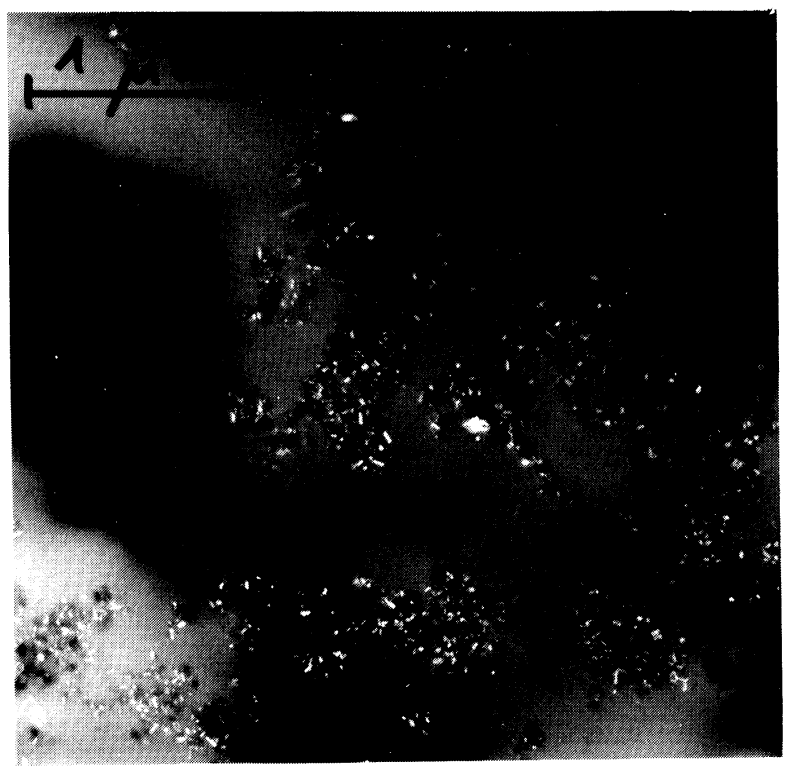

FIGURE 6 Dark field micrograph, Product B.

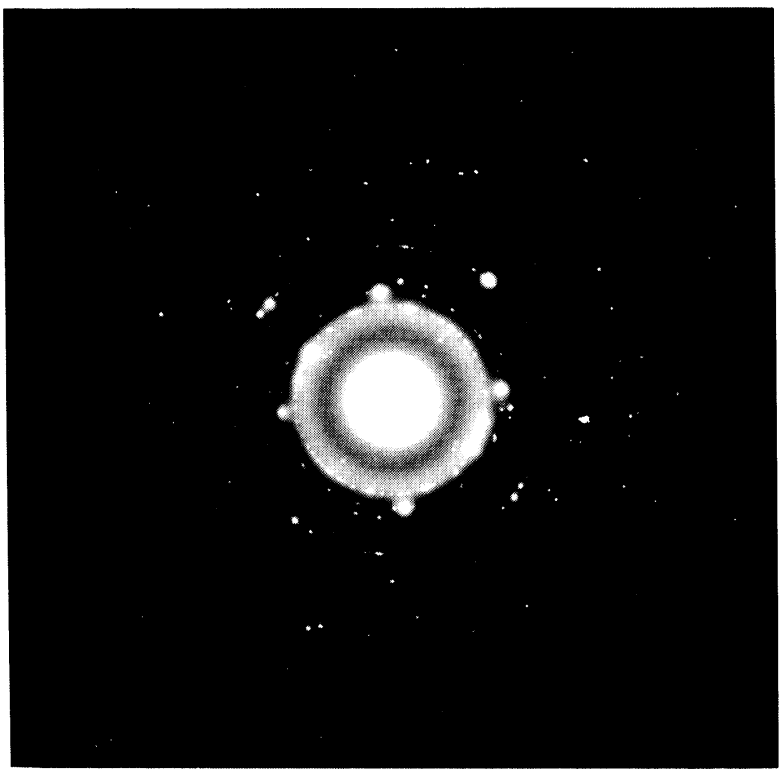

FIGURE 7 Selected area diffraction pattern, Product C.

perforated. The position of the final thin foil may be controlled by selective thinning, so that for example a region close to the resistor-substrate interface may be examined. The thin foil is now ready for examination in the electron microscope.

\section{SPECIMEN EXAMINATION}

The interaction of the incident electron beam with a thick-film resistor sample in the transmission electron microscope is illustrated schematically in Figure 2. The particle size and morphology of crystalline phases in the resistor may be determined from bright field images using the transmitted beam. The location

\section{Product B, glassy matrix}

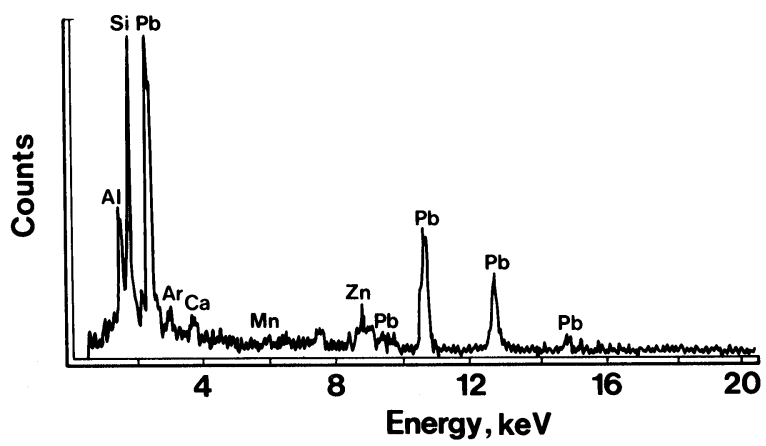

FIGURE $8 \quad \mathrm{X}$-ray energy spectrum from glassy phase in Product B. 
of specific phases and orientations may be determined from dark field images using one or more of the beams diffracted by crystalline phases in the structure. Useful stereoscopic images of the structure may be reconstructed from stereopairs taken in the HVEM using specimen tilting. The structure of the crystalline phases present may be determined from analysis of selected diffraction patterns. Furthermore the characteristic X-rays emitted when the electron beam is additionally focussed to a spot 0.1 to $0.2 \mu \mathrm{m}$ in diameter may be analysed to provide spectra of the elements present in a very small, selected volume of the sample. This latter technique is of particular use in allowing separate spectra to be obtained from glass and conducting phase in an ultra-fine resistor microstructure.

Examples of some typical images, diffraction patterns and X-ray spectra are presented in Figures 3 to 8 . The very small crystallite size, 0.01 to $1 \mu \mathrm{m}$, of the particles of the conducting phases in these materials is of particular note. The conducting phases for products $A$ and $B$ were identified from diffraction data and EMMA analysis as crystalline ruthenium dioxide and for product $\mathrm{C}$ as bismuth ruthenate. X-ray spectra obtained from regions of glass phase about $0.2 \mu \mathrm{m}$ removed from the adjacent ruthenium dioxide or ruthenate particles showed that the ruthenium level in the glass was not greater than the background level on the instrument $(\sim 1 \%)$. It is hoped that continued studies with the TEM techniques described herein will shed further light on the conduction mechanism in thick film resistors.

\section{REFERENCES}

1. M. P. Ansell, Electrocomponent Science and Technology 1976, Vol. 3, pp. 131-151.

2. R. W. Vest, Final Technical Report, ARPA order no. 1642, Purdue University, Dec. 1975. 

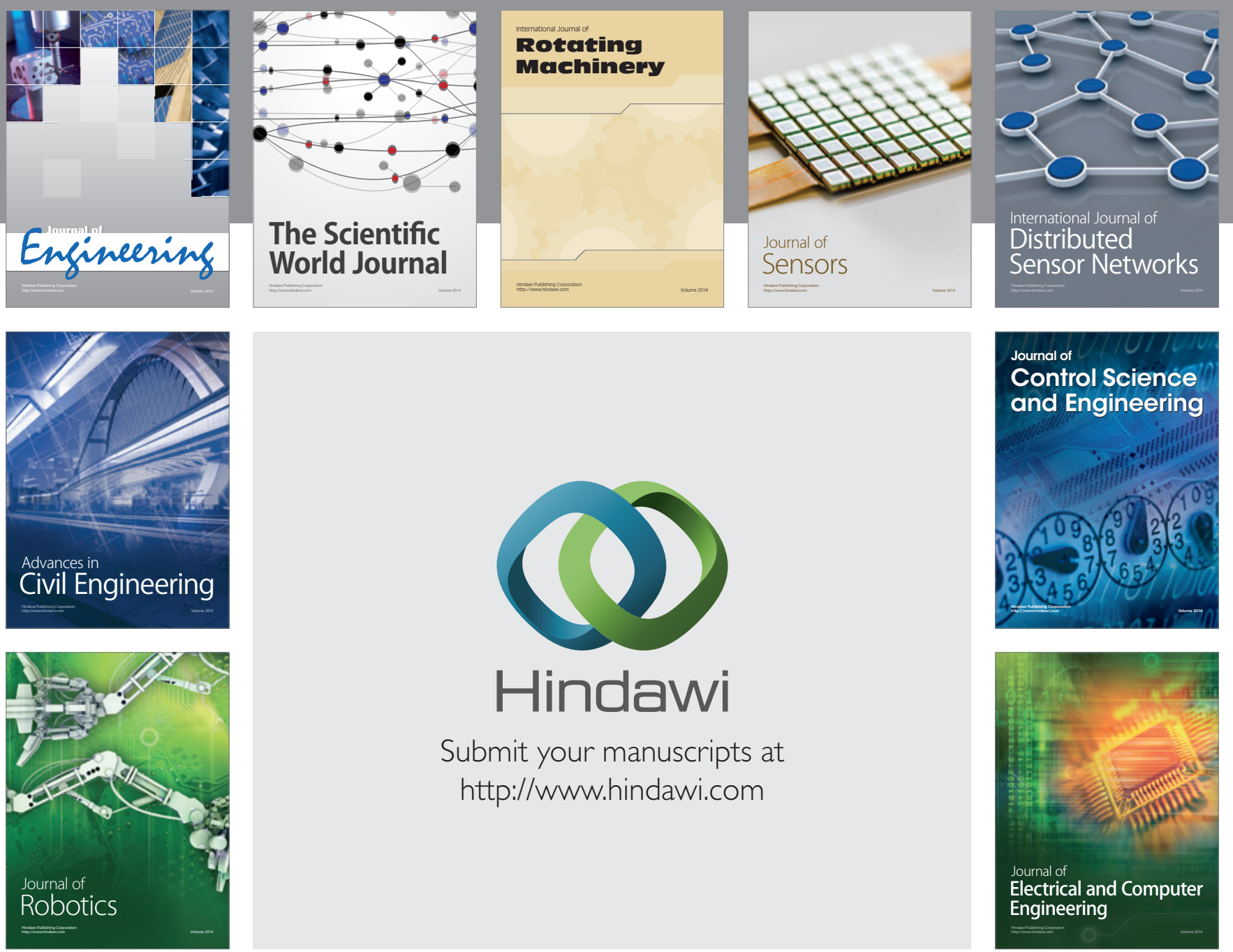

Submit your manuscripts at

http://www.hindawi.com
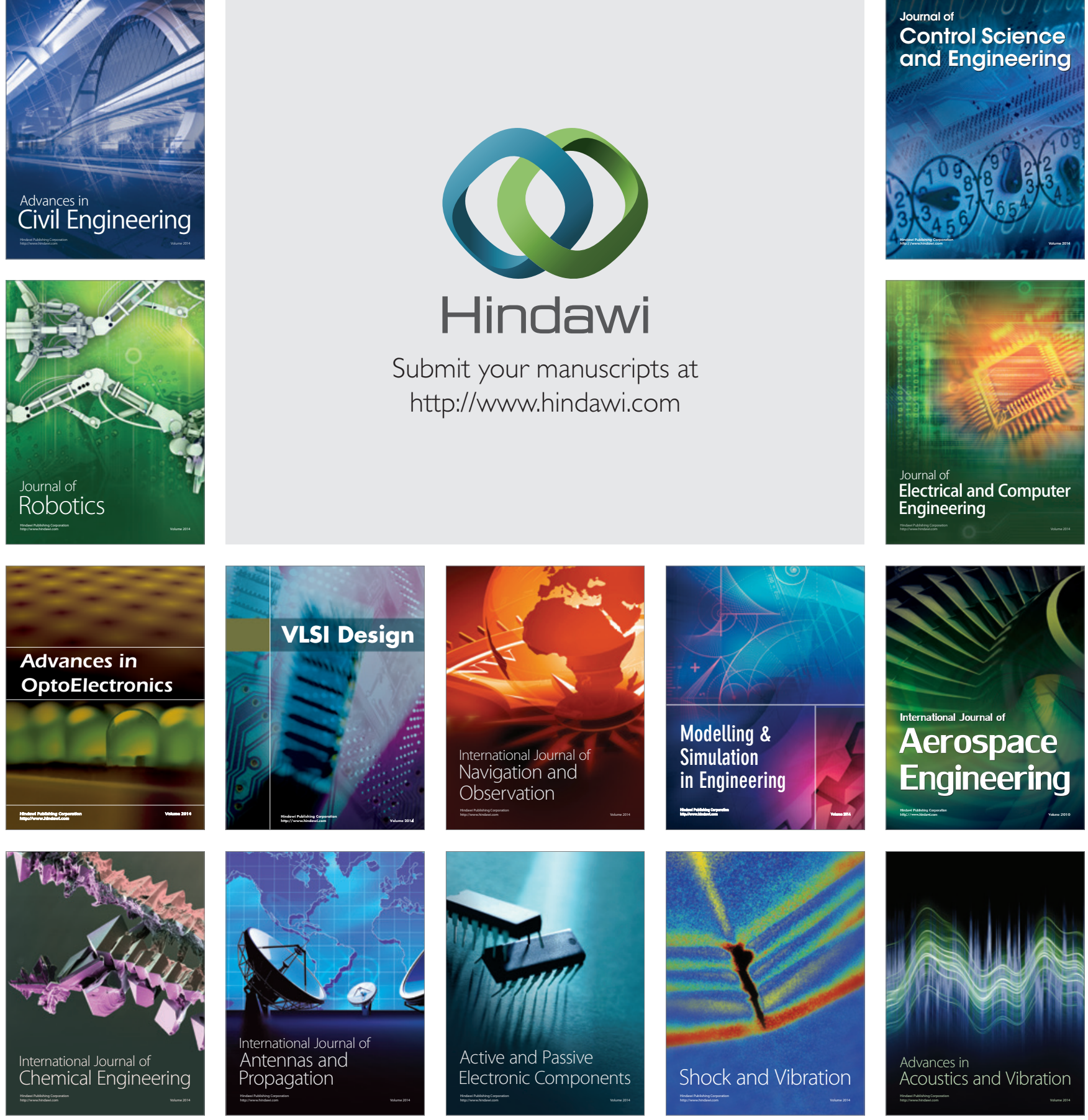